CLINICAL STUDY

\title{
Vitamin D, parathyroid hormone and the metabolic syndrome in middle-aged and older European men
}

\author{
David M Lee, Martin K Rutter ${ }^{1}$, Terence W O’Neill, Steven Boonen ${ }^{2}$, Dirk Vanderschueren ${ }^{3}$, Roger Bouillon ${ }^{4}$, \\ Gyorgy Bartfai ${ }^{5}$, Felipe F Casanueva ${ }^{6,7}$, Joseph D Finn, Gianni Forti ${ }^{8}$, Aleksander Giwercman ${ }^{9}$, Thang S Han ${ }^{10}$, \\ Ilpo T Huhtaniemi ${ }^{11}$, Krzysztof Kula ${ }^{12}$, Michael E J Lean ${ }^{13}$, Neil Pendleton ${ }^{14}$, Margus Punab ${ }^{15}$, Alan J Silman, \\ Frederick $\mathrm{C} W \mathrm{Wu}^{16}$ and the European Male Ageing Study Group \\ ARC Epidemiology Unit, The University of Manchester, Manchester M13 9PT, UK, ${ }^{1}$ Manchester Diabetes Centre, The University of Manchester, \\ Manchester, UK, ${ }^{2}$ Division of Gerontology and Geriatrics and Centre for Musculoskeletal Research, Department of Experimental Medicine, ${ }^{3}$ Department of \\ Andrology and Endocrinology and ${ }^{4}$ Department of Experimental Medicine, Katholieke Universiteit Leuven, Leuven, Belgium, ${ }^{5}$ Department of Obstetrics, \\ Gynaecology and Andrology, Albert Szent-Gyorgy Medical University, Szeged, Hungary, ${ }^{6}$ Department of Medicine, Santiago de Compostela University, \\ Complejo Hospitalario Universitario de Santiago (CHUS), Santiago de Compostela, Spain, ${ }^{7}$ CIBER de Fisiopatología Obesidad y Nutrición (CB06/03), \\ Instituto Salud Carlos III, Santiago de Compostela, Spain, ${ }^{8}$ Andrology Unit, Department of Clinical Physiopathology, University of Florence, Florence, Italy, \\ ${ }^{9}$ Reproductive Medicine Centre, Malmö University Hospital, University of Lund, Malmö, Sweden, ${ }^{10}$ Department of Endocrinology, Royal Free and \\ University College Hospital Medical School, Royal Free Hospital, Hampstead, London, UK, ${ }^{11}$ Department of Reproductive Biology, Imperial College London, \\ Hammersmith Campus, London, UK, ${ }^{12}$ Department of Andrology and Reproductive Endocrinology, Medical University of Lodz, Lodz, Poland, ${ }^{13}$ Department \\ of Human Nutrition, University of Glasgow, Glasgow, UK, ${ }^{14}$ Clinical Gerontology, The University of Manchester, Hope Hospital, Salford, UK, ${ }^{15}$ Andrology \\ Unit, United Laboratories of Tartu University Clinics, Tartu, Estonia and ${ }^{16}$ Department of Endocrinology, Manchester Royal Infirmary, The University \\ of Manchester, Manchester, UK \\ (Correspondence should be addressed to D M Lee; Email: david.m.lee@manchester.ac.uk)
}

\begin{abstract}
Objectives: Low serum 25-hydroxyvitamin D (25(OH)D) and elevated parathyroid hormone (PTH) levels have been linked to insulin resistance, the metabolic syndrome (MetS) and its components. Data in healthy, community-dwelling Europeans are lacking, and previous studies have not excluded subjects receiving drug treatments that may distort the relationship between $25(\mathrm{OH}) \mathrm{D} / \mathrm{PTH}$ and MetS. The aim of our analysis was to examine the association of $25(\mathrm{OH}) \mathrm{D}$ and PTH with Adult Treatment Panel III-defined MetS in middle-aged and older European men.

Design: This was a population-based, cross-sectional study of 3369 men aged 40-79 years enrolled in the European Male Ageing Study.

Results: After exclusion of subjects with missing data, 3069 men with a mean ( \pm s.D.) age of $60 \pm 11$ years were included in the analysis. Age-adjusted 25(OH)D levels were inversely associated with waist circumference, systolic blood pressure (BP), triglycerides, and glucose (all $P<0.01$ ). Age-adjusted PTH levels were only associated with waist and diastolic BP (both $P<0.05$ ). After adjusting for age, centre, season and lifestyle factors the odds for MetS decreased across increasing 25(OH)D quintiles (odds ratios 0.48 (95\% confidence intervals $0.36-0.64)$ highest versus lowest quintile; $\left.P_{\text {trend }}<0.001\right)$. This relationship was unchanged after adjustment for PTH, but was attenuated after additional adjustment for homoeostasis model assessment of insulin resistance $\left(0.60(0.47-0.78) ; P_{\text {trend }}<0.001\right)$. There was no association between PTH and MetS.

Conclusions: Our results demonstrate an inverse relationship between 25(OH)D levels and MetS, which is independent of several confounders and PTH. The relationship is partly explained by insulin resistance. The clinical significance of these observations warrants further study.
\end{abstract}

European Journal of Endocrinology $161947-954$

\section{Introduction}

25-Hydroxyvitamin D (25(OH)D) and parathyroid hormone $(\mathrm{PTH})$ are important physiological regulators of extracellular calcium homoeostasis. A number of recent population-based, cross-sectional studies suggest additional metabolic roles for these hormones (1-5). Data from the California-based Rancho Bernardo study, in which subjects have high sunlight exposure and high vitamin D levels, indicated that $25(\mathrm{OH}) \mathrm{D}$ was not related to prevalent metabolic syndrome (MetS) (4), whereas US population-based data from NHANES, in which vitamin D levels were lower, indicated a marked inverse relationship between these variables (5). Both studies also suggested that PTH was related to prevalent MetS in older men. There is some biological plausibility for these relationships because low vitamin D levels, and to a lesser extent elevated PTH levels, have been associated with glucose intolerance and insulin resistance (6-10). 
Although the studies by Reis $(4,5)$ and others $(3,11)$ were population based and some were adjusted for several confounders including PTH and 25(OH)D levels, subjects taking anti-hypertensive and lipid-lowering medications were not excluded from these analyses. We are not aware of any previous studies that have specifically explored the effects of these groups of drugs on the relationship between the vitamin D/PTH axis and MetS, though it is possible that any associations may potentially be distorted by medication use targeting component parts of the MetS.

The purpose of our study was to examine the crosssectional associations of 25(OH)D and PTH levels with MetS in a large population-based cohort of European men and to contrast the strength of any associations after excluding those taking medications that might influence these relationships.

\section{Methods}

\section{Subjects}

The European Male Ageing Study (EMAS) is a prospective, non-interventional cohort study of male ageing in Europe. Details regarding recruitment, response rates and assessments have been previously described (12). Briefly, noninstitutionalised men aged 40-79 years were recruited from municipal or population registers in eight centres: Florence (Italy); Leuven (Belgium); Lodz (Poland); Malmö (Sweden); Manchester (UK); Santiago de Compostela (Spain); Szeged (Hungary); Tartu (Estonia). For the baseline survey, stratified random sampling was used with the aim of recruiting equal numbers of men into each of four age bands $(40-49,50-59,60-69$ and 70-79 years). Subjects were invited by letter to complete a short postal questionnaire and to attend for screening at a local clinic. The mean adjusted response rate across the eight centres was $43 \%$ (range 24-60\%). The study was funded by the European Union, and ethical approval for the study was obtained in accordance with local institutional requirements in each centre.

\section{Assessments}

The postal questionnaire included items concerning demographic, health and lifestyle information. Subjects were asked about tobacco use (response set $=$ current/past/non-smoker) and typical alcohol consumption during the preceding month (response set $=$ every day $/ 5-6$ days/week/3-4 days/week/1-2 days/ week $/<$ once/week/not at all). Those who agreed to participate subsequently attended a research clinic to complete an interviewer-assisted questionnaire (IAQ) and physiological assessments. The IAQ included the physical activity scale for the elderly (PASE) (13) to assess physical activity levels. Blood pressure measurements were performed after a 5-min rest period to the nearest $1 \mathrm{mmHg}$ with subjects seated using an Omron
500I automated sphygmomanometer (Omron Healthcare Ltd, Milton Keynes, UK). Height was measured barefoot to the nearest $1 \mathrm{~mm}$ using a stadiometer (Leicester Height Measure, SECA UK Ltd, Birmingham, UK), and weight to the nearest $0.1 \mathrm{~kg}$ using an electronic scale (SECA, model no. 8801321009, SECA UK Ltd) with subjects wearing light clothing. Each centre's electronic scales and stadiometers were calibrated on a monthly basis. Waist circumference was measured thrice to the nearest $1 \mathrm{~mm}$ using anthropometric tape, mid-way between the lowest rib and the iliac crest with the subject standing, and the median used to score. Current prescription and non-prescription drug use was recorded with participants bringing in all medications for confirmation.

\section{Biochemistry}

Phlebotomy was performed prior to $1000 \mathrm{~h}$ to obtain a fasting blood sample from all subjects. Processed serum was stored and protected from light at $-80^{\circ} \mathrm{C}$ prior to analysis and shipped on dry ice to central laboratories for measurement of 25(OH)D (Katholieke Universiteit Leuven) and PTH (University of Santiago de Compostela). Serum 25(OH)D levels were determined using RIA (RIA kit: DiaSorin, Stillwater, MN, USA). Intra- and inter-assay coefficients of variation $(\mathrm{CV})$ for $25(\mathrm{OH}) \mathrm{D}$ were 11 and $8 \%$ respectively. The detection limit of the RIA kit was $5.0 \mathrm{nmol} / \mathrm{l} 25(\mathrm{OH}) \mathrm{D}$. Serum was assayed for PTH using a chemiluminescence immunoassay (Nichols Advantage Bio-Intact PTH assay, Quest Diagnostics, Madison, NJ, USA). Intra- and inter-assay CV for PTH were 6 and $2.8 \%$ respectively. The detection limit of the chemiluminescence immunoassay was $0.16 \mathrm{pmol} / \mathrm{l}$.

Analyses for cholesterol, high-density lipoprotein (HDL) cholesterol and triglycerides were performed locally in all centres using commercially available enzymatic methods. Fasting glucose was measured using standard hexokinase enzymatic assays. Insulin was assayed using quimioluminiscence (University of Santiago de Compostela). Insulin resistance was calculated using the homoeostasis model assessment of insulin resistance (HOMA-IR) (14). All clinical pathology laboratories were accredited by the relevant national authorities and adhered to current guidelines on Good Laboratory Practice as specified by EU Directive 2004/9/EC (15).

\section{Metabolic syndrome}

To assess the prevalence of MetS among the EMAS cohort, we used the current ATPIII guidelines (16). The ATPIII definition of MetS was met if subjects had at least three of the following: a waist circumference $>102 \mathrm{~cm}$, a triglyceride level $\geq 1.7 \mathrm{mmol} / \mathrm{l}$, a HDL cholesterol level $<1.03 \mathrm{mmol} / \mathrm{l}$, systolic blood pressure $\geq 130 \mathrm{mmHg}$ and/or diastolic blood pressure $\geq 85 \mathrm{mmHg}$, and fasting glucose $\geq 5.6 \mathrm{mmol} / \mathrm{l}$. 


\section{Analysis}

Statistical analyses were performed using Intercooled Stata version 9.2 (StataCorp., College Station, TX, USA). Subjects with missing 25(OH)D and PTH measurements $(n=151)$, or incomplete MetS data $(n=149)$ were excluded, leaving 3069 men in the main analysis. $25(\mathrm{OH}) \mathrm{D}$ and PTH were examined as continuous variables or classified into quintiles. Age, the PASE score and individual components of the MetS were treated as continuous variables in linear regression models. Season of attendance at the clinic was defined as winter (January-March), spring (April-June), summer (July-September) and autumn (October-December). The associations of $25(\mathrm{OH}) \mathrm{D}$ and $\mathrm{PTH}$ with covariates were examined using Pearson correlation and one-way ANOVA.

We initially explored the association of both $25(\mathrm{OH}) \mathrm{D}$ and PTH levels with MetS components using linear regression (adjusting for age), with results expressed as $\beta$ coefficients and 95\% confidence intervals (CI). Mean levels ( \pm s.E.M.) of each MetS component by quintile of either $25(\mathrm{OH}) \mathrm{D}$ or PTH were then estimated using multiple linear regression models adjusting for potential confounders (age, physical activity and season). In addition, to allow for the likelihood that observations are independent across centres, but not necessarily within centres, robust standard errors were requested using Stata's cluster subcommand with centre as the clustering variable. Linear trends were assessed by using the quintiles of $25(\mathrm{OH}) \mathrm{D}$ or PTH as ordinal terms in the regression model. Finally, multivariable logistic regression models assessed the individual and combined associations of $25(\mathrm{OH}) \mathrm{D}$ and PTH with MetS after serial adjustments for potential confounders, including HOMA-IR, with results expressed as odds ratios (ORs) and 95\% CI. Effect modification by age was also assessed by inclusion of interaction terms between $25(\mathrm{OH}) \mathrm{D}$ or PTH concentration and age (by decade) in the logistic regression models.

\section{Results}

\section{Subjects}

The clinical characteristics of the 3069 men included in the analysis sample are shown in Table 1.

\section{5(OH)D and PTH}

25(OH)D was inversely related to PTH $(r=-0.18$, $P<0.001)$ and varied markedly by season of measurement (mean \pm s.D.): summer, $85 \pm 33$ versus winter, $50 \pm 26 \mathrm{nmol} / \mathrm{l}(P<0.001) .25(\mathrm{OH}) \mathrm{D}$ was inversely related to body mass index (BMI) $(r=-0.10$, $P<0.001)$, and positively related to PASE score $(r=0.10, P<0.001)$. There were significant betweencentre differences in mean levels of $25(\mathrm{OH}) \mathrm{D}$, ranging from $77 \mathrm{nmol} / \mathrm{l}$ in Malmö to $47 \mathrm{nmol} / \mathrm{l}$ in Tartu (adjusted for season, $P<0.001$ ).
Table 1 Baseline characteristics $(n=3069)$.

\begin{tabular}{|c|c|}
\hline Variable & Mean (S.D.) \\
\hline Age (years) & $60.0(11.0)$ \\
\hline Waist circumference (cm) & $98.4(10.9)$ \\
\hline Systolic blood pressure (mmHg) & $146(21)$ \\
\hline Diastolic blood pressure (mmHg) & $87(12)$ \\
\hline HDL cholesterol (mmol/l) & $1.4(0.4)$ \\
\hline Triglycerides $(\mathrm{mmol} / \mathrm{l})$ & $1.6(1.1)$ \\
\hline Glucose (mmol/l) & $5.6(1.4)$ \\
\hline Body mass index $\left(\mathrm{kg} / \mathrm{m}^{2}\right)$ & $27.6(4.1)$ \\
\hline 25(OH)D (nmol/l) & $62.3(31.3)$ \\
\hline Parathyroid hormone (pmol/l) & $3.1(1.5)$ \\
\hline \multirow[t]{2}{*}{ Physical activity scale for the elderly } & $195(92)$ \\
\hline & $\%$ \\
\hline ATPIII metabolic syndrome & 31.7 \\
\hline Waist circumference $>102 \mathrm{~cm}$ & 33.6 \\
\hline Blood pressure $\geq 130 / 85 \mathrm{mmHg}^{\mathrm{a}}$ & 84.9 \\
\hline HDL cholesterol $<1.03 \mathrm{mmol} / \mathrm{l}$ & 12.9 \\
\hline Triglycerides $\geq 1.7 \mathrm{mmol} / \mathrm{l}$ & 30.3 \\
\hline Glucose $\geq 5.6 \mathrm{mmol} / \mathrm{l}^{\mathrm{b}}$ & 36.0 \\
\hline Diabetes $^{c}$ & 7.6 \\
\hline Current smoker & 21.1 \\
\hline Alcohol consumption ( $\geq 1$ day/week) & 56.2 \\
\hline Lipid-lowering medication $^{d}$ & 13.0 \\
\hline
\end{tabular}

${ }^{a}$ Measured blood pressure and/or using anti-hypertensive drugs.

${ }^{\mathrm{b}}$ Measured blood glucose and/or using anti-diabetic drugs.

'Self-report and/or using anti-diabetic drugs.

Includes fibrate derivatives, bile acid sequestrants, niacin and HMG-CoA reductase inhibitors.

Higher levels of PTH were observed in the winter $(3.2 \pm 1.7 \mathrm{pmol} / \mathrm{l})$ as opposed to the summer months $(2.9 \pm 1.5 \mathrm{pmol} / \mathrm{l})$, and these seasonal differences were statistically significant $(P=0.03)$. PTH levels increased with age $(r=0.13, P<0.001)$, BMI $(r=0.08$, $P<0.001)$ and were inversely related to PASE score $(r=-0.13, P<0.001)$. Current smokers had lower levels of both $25(\mathrm{OH}) \mathrm{D}$ and $\mathrm{PTH}$ than non-smokers $(P<0.01)$. Subjects reporting drinking one or more alcoholic drinks per week had higher 25(OH)D and lower PTH levels than those drinking less frequently (both $P<0.01)$. As with $25(\mathrm{OH}) \mathrm{D}$, mean levels of PTH varied between centres ranging from $2.7 \mathrm{pmol} / \mathrm{l}$ in Szeged to $3.4 \mathrm{pmol} / \mathrm{l}$ in Leuven (adjusted for season, $P<0.001)$. Using linear regression, we did not find a significant association between the latitude of each centre, which ranged from $42.88^{\circ} \mathrm{N}$ (Santiago) to $58.38^{\circ} \mathrm{N}$ (Tartu), and either $25(\mathrm{OH})(\beta=-0.10$, $P=0.3)$ or PTH $(\beta=-0.01, P=0.1)$ after adjusting for season of attendance.

\section{Metabolic syndrome}

The MetS was present in just under one-third of subjects (Table 1). Among those not using anti-hypertensive, diabetes and/or lipid-lowering medications, this fell to one quarter $(24.7 \%)$. The prevalence of individual MetS components according to the current ATPIII guidelines ranged from $13 \%$ of subjects with low HDL cholesterol to $85 \%$ of subjects with hypertension. Age-adjusted associations between 25(OH)D and PTH 
Table 2 Age-adjusted associations between 25-hydroxyvitamin D (25(OH)D) or parathyroid hormone (PTH) and components of the metabolic syndrome: linear regressions.

\begin{tabular}{|c|c|c|}
\hline \multirow[b]{3}{*}{ Dependent variables } & \multicolumn{2}{|c|}{ Independent variables } \\
\hline & $25(\mathrm{OH}) \mathrm{D}-($ per $10 \mathrm{nmol} / \mathrm{l})$ & PTH - (per pmol/l) \\
\hline & \multicolumn{2}{|c|}{$\beta$ Coefficients $(95 \% \mathrm{Cl})^{\mathrm{a}}$} \\
\hline $\begin{array}{l}\text { Waist circumference }(\mathrm{cm}) \\
\text { Systolic blood pressure }(\mathrm{mmHg}) \\
\text { Diastolic blood pressure }(\mathrm{mmHg}) \\
\text { HDL cholesterol }(\mathrm{mmol} / \mathrm{l}) \\
\text { Triglycerides }(\mathrm{mmol} / \mathrm{l}) \\
\text { Glucose }(\mathrm{mmol} / \mathrm{l})\end{array}$ & $\begin{array}{c}-0.413(-0.536,-0.291)^{\star} \\
-0.548(-0.773,-0.323)^{\star} \\
-0.214(-0.354,-0.075)^{\star} \\
0.006(0.002,0.010)^{*} \\
-0.037(-0.050,-0.025)^{\star} \\
-0.032(-0.048,-0.016)^{\star}\end{array}$ & $\begin{array}{l}0.596(0.344,0.847)^{\star} \\
0.406(-0.058,0.870)^{\star} \\
0.525(0.238,0.811)^{\star} \\
-0.009(-0.017,-0.001)^{\star} \\
-0.008(-0.033,0.018)^{\star} \\
-0.019(-0.052,0.013)^{\star}\end{array}$ \\
\hline
\end{tabular}

${ }^{\star} P<0.05$. Note: although the distribution of triglycerides was positively skewed, using log-transformed triglycerides in the above regressions did not change the significance of the associations.

${ }^{a}$ Adjusted for age.

and components of the MetS are presented in Table 2. Increasing 25(OH)D levels were associated with lower values for waist circumference, systolic blood pressure, diastolic blood pressure, triglycerides and glucose, and higher values for HDL cholesterol. However, increasing levels of PTH were only significantly associated with higher values for waist circumference and diastolic blood pressure, and lower values for HDL cholesterol. When the regressions of 25(OH)D and PTH versus blood pressure, lipids and glucose were additionally adjusted for waist circumference, the associations between 25(OH)D and both diastolic blood pressure and HDL cholesterol, and PTH and HDL cholesterol was no longer significant (all $P>0.07$; data not shown).

Adjusted means for individual components of MetS across 25(OH)D or PTH quintiles are shown in
Table 3. Waist circumference, systolic blood pressure, triglycerides and glucose levels were inversely associated with increasing $25(\mathrm{OH}) \mathrm{D}$ quintiles (all $P_{\text {trend }} \leq 0.05$ ), and these relationships were essentially unchanged after additional adjustment for smoking, alcohol consumption and other MetS components (all $P_{\text {trend }}<0.05$, data not shown). Increasing PTH quintiles were positively related to waist circumference, systolic blood pressure and diastolic blood pressure (all $P_{\text {trend }} \leq 0.02$ ), and these trends remained significant for waist circumference and diastolic blood pressure (both $P_{\text {trend }}<0.02$ ) after additional adjustment for smoking, alcohol consumption and other MetS components, but not for systolic blood pressure $\left(P_{\text {trend }}=0.6\right.$, data not shown).

The associations of 25(OH)D or PTH with MetS are summarised in Table 4. The adjusted odds for MetS

Table 3 Adjusted means (S.E.M.) for components of the metabolic syndrome versus quintiles of 25(OH)D and PTH.

\begin{tabular}{|c|c|c|c|c|c|c|}
\hline \multirow[b]{3}{*}{ Dependent variable } & \multicolumn{5}{|c|}{ Quintiles of $25(\mathrm{OH}) \mathrm{D}$ (range $\mathrm{nmol} / \mathrm{l}$ ) } & \multirow[b]{3}{*}{$P_{\text {trend }}$} \\
\hline & $n=617$ & $n=620$ & $n=615$ & $n=610$ & $n=607$ & \\
\hline & $\mathrm{I}(<35.7)$ & II (35.7-49.4) & III (49.5-65.1) & IV (65.2-85.9) & $V(>85.9)$ & \\
\hline Waist circumference $(\mathrm{cm})$ & $99.2(0.7)$ & $99.3(0.7)$ & $99.0(0.7)$ & $98.2(1.0)$ & $96.0(1.1)$ & 0.05 \\
\hline Systolic blood pressure $(\mathrm{mmHg})$ & $148.1(2.2)$ & $146.4(2.4)$ & $145.6(1.9)$ & $145.7(1.5)$ & $142.8(1.4)$ & 0.05 \\
\hline Diastolic blood pressure $(\mathrm{mmHg})$ & $87.9(1.5)$ & $87.5(1.6)$ & $87.4(1.6)$ & $86.9(1.1)$ & $86.1(0.7)$ & 0.3 \\
\hline HDL cholesterol $(\mathrm{mmol} / \mathrm{l})$ & $1.40(0.04)$ & $1.38(0.05)$ & $1.40(0.03)$ & $1.39(0.05)$ & $1.46(0.06)$ & 0.4 \\
\hline Triglycerides $(\mathrm{mmol} / \mathrm{l})$ & $1.73(0.08)$ & $1.65(0.13)$ & $1.58(0.09)$ & $1.54(0.10)$ & $1.30(0.06)$ & 0.001 \\
\hline \multirow[t]{4}{*}{ Glucose $(\mathrm{mmol} / \mathrm{l})$} & $5.84(0.12)$ & $5.70(0.11)$ & $5.61(0.13)$ & $5.63(0.10)$ & $5.48(0.10)$ & 0.002 \\
\hline & \multicolumn{5}{|c|}{ Quintiles of PTH (range pmol/l) } & \\
\hline & $n=614$ & $n=614$ & $n=614$ & $n=614$ & $n=613$ & \\
\hline & $\mathrm{I}(<2.01)$ & II (2.01-2.55) & III $(2.56-3.10)$ & IV (3.11-3.86) & $V(>3.86)$ & \\
\hline Waist circumference $(\mathrm{cm})$ & $97.6(0.7)$ & $98.0(0.9)$ & $97.9(0.9)$ & $98.9(0.7)$ & $99.5(0.8)$ & 0.02 \\
\hline Systolic blood pressure (mmHg) & $145.3(2.1)$ & $144.7(2.0)$ & $145.6(1.6)$ & $145.1(2.0)$ & $148.0(2.0)$ & 0.05 \\
\hline Diastolic blood pressure $(\mathrm{mmHg})$ & $86.3(1.4)$ & 86.5 (1.3) & $86.5(1.0)$ & $87.6(1.2)$ & $88.8(1.5)$ & 0.004 \\
\hline HDL cholesterol (mmol/l) & $1.41(0.05)$ & $1.41(0.05)$ & $1.43(0.05)$ & $1.40(0.04)$ & $1.38(0.04)$ & 0.3 \\
\hline Triglycerides $(\mathrm{mmol} / \mathrm{l})$ & $1.66(0.14)$ & $1.61(0.10)$ & $1.49(0.09)$ & $1.53(0.07)$ & $1.53(0.05)$ & 0.2 \\
\hline Glucose $(\mathrm{mmol} / \mathrm{l})$ & $5.84(0.13)$ & $5.68(0.17)$ & $5.61(0.11)$ & $5.51(0.07)$ & $5.63(0.06)$ & 0.1 \\
\hline
\end{tabular}

Values shown are means (S.E.M.). Adjusted for age, physical activity, season and centre. 25(OH)D, 25-hydroxyvitamin D; PTH, parathyroid hormone. Note: although the distribution of triglycerides was positively skewed, using log-transformed triglycerides in the above regressions, $P_{\text {trend }}$, remained unchanged. 
Table 4 Adjusted odds ratios (95\% confidence intervals) for the association of 25-hydroxyvitamin D (25(OH)D) and parathyroid hormone (PTH) with the metabolic syndrome.

\begin{tabular}{lcccccc}
\hline & \multicolumn{5}{c}{ Quintiles of 25(OH)D (range nmol/I) } \\
\cline { 2 - 6 } & I $(<35.7)$ & II (35.7-49.4) & III (49.5-65.1) & IV (65.2-85.9) & V (>85.9) & $\boldsymbol{P}_{\text {trend }}$ \\
\hline Mean 25(OH)D (nmol/l) & 26.2 & 42.7 & 57.2 & 74.5 & 111.9 & \\
Model 1 & 1.00 (referent) & $0.97(0.65-1.43)$ & $0.75(0.51-1.10)$ & $0.63(0.39-1.01)$ & $0.48(0.36-0.64)$ & $<0.001$ \\
Model 2 & 1.00 (referent) & $0.96(0.65-1.41)$ & $0.75(0.50-1.11)$ & $0.62(0.40-0.97)$ & $0.47(0.37-0.62)$ & $<0.001$ \\
Model 3 & 1.00 (referent) & $0.94(0.62-1.43)$ & $0.78(0.56-1.08)$ & $0.61(0.36-1.04)$ & $0.60(0.47-0.78)$ & $<0.001$ \\
\hline
\end{tabular}

\begin{tabular}{|c|c|c|c|c|c|c|}
\hline & \multicolumn{5}{|c|}{ Quintiles of PTH (range $\mathrm{pmol} / \mathrm{l}$ ) } & \multirow[b]{2}{*}{$P_{\text {trend }}$} \\
\hline & $\mathrm{I}(<2.01)$ & II (2.01-2.55) & III $(2.56-3.10)$ & IV (3.11-3.86) & $V(>3.86)$ & \\
\hline Mean PTH (pmol/l) & 1.59 & 2.29 & 2.81 & 3.46 & 5.22 & \\
\hline Model 1 & 1.00 (referent) & $0.92(0.66-1.26)$ & $0.77(0.50-1.19)$ & $0.88(0.59-1.31)$ & $0.95(0.59-1.55)$ & 0.8 \\
\hline Model 2 & 1.00 (referent) & $0.88(0.65-1.20)$ & $0.72(0.47-1.11)$ & $0.80(0.55-1.18)$ & $0.82(0.51-1.33)$ & 0.4 \\
\hline Model 3 & 1.00 (referent) & $0.97(0.72-1.32)$ & $0.86(0.55-1.35)$ & $1.03(0.84-1.26)$ & $0.98(0.71-1.36)$ & 0.9 \\
\hline
\end{tabular}

Model 1: adjusted for age, smoking, alcohol consumption, physical activity, season and centre. Model 2: adjusted for all variables in Model 1 plus PTH in 25(OH)D analysis and 25(OH)D in PTH analysis. Model 3: adjusted for all variables in Model 2 plus HOMA-IR. Note: there was no evidence that age modified the relationship between either $25(\mathrm{OH}) \mathrm{D}$ or PTH and the metabolic syndrome in any of the models $\left(P_{\text {interaction }}>0.1\right.$ in all cases).

decreased by more than $50 \%$ across increasing quintiles of $25(\mathrm{OH}) \mathrm{D}$ (Model 1), and this relationship was unchanged after adjustment for PTH (Model 2), but was attenuated $(\sim 20 \%)$ after additional adjustment for HOMA-IR (Model 3). There was a significant linear trend across $25(\mathrm{OH}) \mathrm{D}$ quintiles for each model (Table 4), primarily driven by the significant OR in the highest quintile. There was no evidence that the association of $25(\mathrm{OH}) \mathrm{D}$ with MetS differed by age decade $\left(P_{\text {interaction }}>0.1\right)$. No association between PTH and MetS was observed in any of the models, and there was no evidence that the PTH-MetS association was modified by age $\left(P_{\text {interaction }}>0.1\right)$.

When the above logistic regression models were repeated following exclusion of subjects receiving diabetes, anti-hypertensive and/or lipid-lowering medications $(n=1960)$, the results were broadly unchanged. In Model 1, the adjusted odds for MetS decreased $\sim 40 \%$ across increasing quintiles of 25(OH)D (OR 0.56 (95\% CI 0.33, 0.94) for highest versus lowest quintile; $\left.P_{\text {trend }}=0.01\right)$. The association was unchanged following adjustment for PTH (Model 2) (0.57 $(0.35,0.93)$ for highest versus lowest quintile; $\left.P_{\text {trend }}=0.01\right)$, but additional adjustment for HOMAIR (Model 3) again attenuated the relationship (0.70 $(0.47,1.04)$ for highest versus lowest quintile; $\left.P_{\text {trend }}=0.04\right)$. As with the analysis using the entire sample, we observed no relationship between PTH and MetS in models excluding men using specific medications (all $P_{\text {trend }}>0.3$, data not shown).

\section{Discussion}

\section{Main findings}

In this population-based study of middle-aged and older European men, we showed that age-adjusted $25(\mathrm{OH}) \mathrm{D}$ levels were significantly associated with all
MetS components. Waist circumference, systolic blood pressure, triglycerides and glucose levels were inversely associated with $25(\mathrm{OH}) \mathrm{D}$ after additional adjustment for physical activity, season and centre. The odds of MetS decreased $\sim 50 \%$ across increasing 25(OH)D quintiles, and this relationship was in part explained by insulin resistance. Waist circumference, diastolic blood pressure and systolic blood pressure were associated with PTH levels after multivariable adjustment, but there was no evidence of an association between PTH levels and MetS.

\section{Previous studies of 25(OH)D and MetS}

Several factors might explain why population-based studies exploring the association of $25(\mathrm{OH}) \mathrm{D}$ with MetS, and its components have yielded conflicting results. Ford and co-workers showed in NHANES subjects that the adjusted risk for MetS was inversely associated with $25(\mathrm{OH}) \mathrm{D}$ levels, but this study was limited by the failure to adjust for PTH (1). This is potentially important because low calcium and vitamin D levels are physiological stimuli for PTH synthesis, and there is evidence that elevated PTH may influence the risk for MetS (17-24). In a subsequent analysis that adjusted for PTH levels, Reis and co-workers found no association between MetS with 25(OH)D levels in men or women (4). These Rancho Bernado study participants resided in southern California where high levels of exposure to u.v. radiation probably contributed to the relatively high $25(\mathrm{OH}) \mathrm{D}$ levels (mean $\sim 105 \mathrm{nmol} / \mathrm{l}$ ). In a separate study in NHANES subjects, Reis and co-workers reported a strong inverse relationship between 25(OH)D levels and prevalent MetS that was independent of PTH levels and other important confounders (5). The mean $25(\mathrm{OH}) \mathrm{D}$ level among this representative sample of the non-institutionalised US population was 
$\sim 62 \mathrm{nmol} / \mathrm{l}$. These findings were in stark contrast to those of the Rancho Bernardo study and suggested that a threshold may exist whereby vitamin D deficiency may influence incident MetS (5), whereas higher levels may not (4). Our results and mean $25(\mathrm{OH}) \mathrm{D}$ levels $(62 \mathrm{nmol} / \mathrm{l})$ are very similar to Reis' recent NHANES study (5) and, therefore, lend some support to the threshold hypothesis. The different 25(OH)D levels reported in the Rancho Bernado study (4) and the NHANES study (5) should be interpreted cautiously, however, as different assays were used to measure $25(\mathrm{OH}) \mathrm{D}$. Whether the relationships observed are explained by variation in sun exposure is uncertain and our results did not change following additional adjustment for latitude - a surrogate measure of sun exposure (data not shown).

The mechanism(s) by which low vitamin D could be associated with MetS remain speculative (5). Data in humans suggest that low $25(\mathrm{OH}) \mathrm{D}$ levels are associated with glucose intolerance and insulin resistance $(6,9,10)$. In support of this, we showed that the relationship between MetS and 25(OH)D was in part explained by insulin resistance. The cross-sectional nature of our data does not exclude the possibility that obesity and hypertension, and associated co-morbid conditions, could reduce levels of outdoor physical activity and sun exposure. This explanation may be less likely because even short duration sun exposure from late spring to early autumn will stimulate vitamin D synthesis and when we additionally excluded many of our less healthy subjects who were receiving therapy for diabetes, hypertension and/or dyslipidaemia, our results were largely unchanged. Residual confounding from low 25(OH)D levels acting as a marker for a less healthy lifestyle and diet not identified by the measured covariates might also explain our findings.

\section{Previous studies of PTH and MetS}

In the Rancho Bernardo study and in NHANES subjects, Reis and co-workers showed that prevalent MetS was positively related to PTH concentration among older men but not women $(4,5)$. In contrast, we found no relationship between MetS and PTH levels in men and no evidence of an age interaction even in minimally adjusted models $\left(P_{\text {interaction }}>0.1\right)$. It is possible that when we excluded men who were using medications targeting component parts of the MetS, our data reflect the true physiology more closely. However, we found no evidence of an association between PTH and MetS even when subjects receiving diabetes, anti-hypertensive and/or lipid-lowering medications were excluded from the analysis.

Our mean PTH levels $(3 \mathrm{pmol} / \mathrm{l} \approx 28 \mathrm{pg} / \mathrm{ml}$ ) were lower than compared with Reis' studies; $51 \mathrm{pg} / \mathrm{ml}$ (4) and $42 \mathrm{pg} / \mathrm{ml}$ (5) respectively, and it is possible, therefore, that a threshold also exists for PTH whereby elevated PTH may influence the development of MetS whereas lower levels do not. In either case, our data do not support an independent association between the MetS and PTH in men.

\section{Strengths and limitations}

We have studied a large, population-based sample of European men. We adjusted for physical activity, $25(\mathrm{OH}) \mathrm{D}$ and PTH status which were assessed by standardised methods (12) and the age-stratified enrolment facilitated robust exploration of age interactions. To allow for possible distortion of the relationship between the vitamin D/PTH axis and MetS by medication use targeting diabetes, hypertension or dyslipidaemia, we repeated our logistic regression models excluding subjects who were currently treated for pre-existing components of the MetS. Although our rationale to exclude these men was theoretical, it was based on the premise that the association between $25(\mathrm{OH}) \mathrm{D} / \mathrm{PTH}$ and MetS may be falsely inflated if subjects with currently treated components of the MetS were included in the analysis. Evidence of a stronger relationship between 25(OH)D and the MetS in analyses using the entire EMAS sample supports this notion, although the overall pattern of associations was unchanged.

Our study has a number of limitations. The crosssectional design limits conclusions about causal relationships. We enrolled non-institutionalised, primarily Caucasian men with a study response rate of $43 \%$, which could limit the generalisability to other groups. $25(\mathrm{OH}) \mathrm{D}$ and PTH were assayed from a single measurement and, consequently, the strength of the observed associations are likely to be conservative. However, given that the prevalence of MetS in our sample was relatively common and we used a logistic regression model to determine ORs from cross-sectional data, it is possible that we may have overestimated the magnitude of the observed associations (25). Finally, we did not adjust for calcium intake, although adjustment for PTH in the $25(\mathrm{OH}) \mathrm{D}$ analysis should partly compensate for this.

\section{Clinical implications}

Studies in animals $(26-28)$ and some $(29,30)$ but not all (31) data in humans suggest that vitamin D therapy could improve glucose intolerance and insulin resistance (29). These studies and the data presented here could inform therapeutic trials of vitamin D on incident MetS and ultimately on incident diabetes and/or cardiovascular disease in subjects with low 25(OH)D levels. However, it is premature to suggest vitamin D therapy to prevent MetS, diabetes or cardiovascular 
disease particularly since the relationship between $25(\mathrm{OH}) \mathrm{D}$ and cardiovascular risk may be non-linear and possibly U-shaped (32).

\section{Conclusion}

We have shown that in a population-based study of European men, low 25(OH)D levels were linked to prevalent MetS and that this relationship was partially mediated by insulin resistance. In contrast to previous studies, PTH levels were not associated with MetS. Further prospective studies are needed to ascertain the relationship between vitamin D and MetS.

\section{Declaration of interest}

The authors have no financial arrangements or conflict of interest to disclose concerning this manuscript.

\section{Funding}

The European Male Ageing Study is funded by the Commission of the European Communities Fifth Framework Program 'Quality of Life and Management of Living Resources' Grant QLK6-CT-2001-00258. Additional support was also provided by the Arthritis Research Campaign (UK).

\section{Acknowledgements}

The EMAS study group: Florence (Gianni Forti, Luisa Petrone, Antonio Cilotti); Leuven (Dirk Vanderschueren, Steven Boonen, Herman Borghs); Lodz (Krzysztof Kula, Jolanta Slowikowska-Hilczer, Renata Walczak-Jedrzejowska); London (Ilpo Huhtaniemi); Malmö (Aleksander Giwercman); Manchester (Frederick Wu, Alan Silman, Neil Pendleton, Terence O'Neill, Joseph Finn, Philip Steer, Abdelouahid Tajar, David Lee, Stephen Pye); Santiago (Felipe Casanueva, Mary Lage); Szeged (Gyorgy Bartfai, Imre Földesi, Imre Fejes); Tartu (Margus Punab, Paul Korrovitz); Turku (Min Jiang). The authors wish to thank the men who participated in the eight countries, the research/nursing staff in the eight centres: C Pott, Manchester; E Wouters, Leuven; M Nilsson, Malmö; M del Mar Fernandez, Santiago de Compostela; M Jedrzejowska, Lodz; H-M Tabo, Tartu; A Heredi, Szeged for their data collection, C Moseley, Manchester for data entry and project co-ordination, and E Van Herck, Leuven for performing the 25(OH)D assays.

\section{References}

1 Ford ES, Ajani UA, McGuire LC \& Liu S. Concentrations of serum vitamin D and the metabolic syndrome among US adults. Diabetes Care 200528 1228-1230.

2 Gannage-Yared MH, Chedid R, Khalife S, Azzi E, Zoghbi F \& Halaby G. Vitamin D in relation to metabolic risk factors, insulin sensitivity and adiponectin in a young Middle-Eastern population. European Journal of Endocrinology 2009160 965-971.

3 Lu L, Yu Z, Pan A, Hu FB, Franco OH, Li H, Li X, Yang X, Chen Y \& Lin X. Plasma 25-hydroxyvitamin D concentration and metabolic syndrome among middle-aged and elderly Chinese individuals. Diabetes Care 200932 1278-1283.

4 Reis JP, von Muhlen D, Kritz-Silverstein D, Wingard DL \& BarrettConnor E. Vitamin D, parathyroid hormone levels, and the prevalence of metabolic syndrome in community-dwelling older adults. Diabetes Care 200730 1549-1555.
5 Reis JP, von Muhlen D \& Miller ER III. Relation of 25-hydroxyvitamin D and parathyroid hormone levels with metabolic syndrome among US adults. European Journal of Endocrinology 2008159 41-48.

6 Chiu KC, Chu A, Go VL \& Saad MF. Hypovitaminosis D is associated with insulin resistance and beta cell dysfunction. American Journal of Clinical Nutrition 200479 820-825.

7 Chiu KC, Chuang LM, Lee NP, Ryu JM, McGullam JL, Tsai GP \& Saad MF. Insulin sensitivity is inversely correlated with plasma intact parathyroid hormone level. Metabolism 200049 1501-1505.

8 Norman AW, Frankel JB, Heldt AM \& Grodsky GM. Vitamin D deficiency inhibits pancreatic secretion of insulin. Science 1980 209 823-825.

9 Liu E, Meigs JB, Pittas AG, McKeown NM, Economos CD, Booth SL \& Jacques PF. Plasma 25-hydroxyvitamin D is associated with markers of the insulin resistant phenotype in nondiabetic adults. Journal of Nutrition 2009139 329-334.

10 Forouhi NG, Luan J, Cooper A, Boucher BJ \& Wareham NJ. Baseline serum 25-hydroxy vitamin $D$ is predictive of future glycemic status and insulin resistance: the Medical Research Council Ely Prospective Study 1990-2000. Diabetes 200857 2619-2625.

11 Hypponen E, Boucher BJ, Berry DJ \& Power C. 25-Hydroxyvitamin D, IGF-1, and metabolic syndrome at 45 years of age: a crosssectional study in the 1958 British Birth Cohort. Diabetes 200857 298-305.

12 Lee DM, O'Neill TW, Pye SR, Silman AJ, Finn JD, Pendleton N, Tajar A, Bartfai G, Casanueva F, Forti G, Giwercman A, Huhtaniemi IT, Kula K, Punab M, Boonen S, Vanderschueren D \& Wu FC. The European Male Ageing Study (EMAS): design, methods and recruitment. International Journal of Andrology 2009 32 11-24.

13 Washburn RA, Smith KW, Jette AM \& Janney CA. The physical activity scale for the elderly (PASE): development and evaluation. Journal of Clinical Epidemiology 199346 153-162.

14 Matthews DR, Hosker JP, Rudenski AS, Naylor BA, Treacher DF \& Turner RC. Homeostasis model assessment: insulin resistance and beta-cell function from fasting plasma glucose and insulin concentrations in man. Diabetologia 198528 412-419.

15 Directive 2004/9/EC of the European Parliament and of the Council on the inspection and verification of good laboratory practice (GLP) 2004.

16 Grundy SM, Cleeman JI, Daniels SR, Donato KA, Eckel RH, Franklin BA, Gordon DJ, Krauss RM, Savage PJ, Smith SC Jr, Spertus JA \& Costa F. Diagnosis and management of the metabolic syndrome: an American Heart Association/National Heart, Lung, and Blood Institute Scientific Statement. Circulation 2005112 2735-2752.

17 Bell NH, Epstein S, Greene A, Shary J, Oexmann MJ \& Shaw S. Evidence for alteration of the vitamin D-endocrine system in obese subjects. Journal of Clinical Investigation 198576 370-373.

18 Bolland MJ, Grey AB, Gamble GD \& Reid IR. Association between primary hyperparathyroidism and increased body weight: a metaanalysis. Journal of Clinical Endocrinology and Metabolism 200590 $1525-1530$.

19 Cheung PS, Thompson NW, Brothers TE \& Vinik AI. Effect of hyperparathyroidism on the control of diabetes mellitus. Surgery $19861001039-1047$.

20 Jorde R, Sundsfjord J, Haug E \& Bonaa KH. Relation between low calcium intake, parathyroid hormone, and blood pressure. Hypertension 200035 1154-1159.

21 Jorde R, Svartberg J \& Sundsfjord J. Serum parathyroid hormone as a predictor of increase in systolic blood pressure in men. Journal of Hypertension 200523 1639-1644.

22 Kamycheva E, Sundsfjord J \& Jorde R. Serum parathyroid hormone level is associated with body mass index. The 5th Tromso study. European Journal of Endocrinology 2004151 167-172.

23 Snijder MB, van Dam RM, Visser M, Deeg DJ, Dekker JM, Bouter LM, Seidell JC \& Lips P. Adiposity in relation to vitamin D status and parathyroid hormone levels: a population-based study in older men and women. Journal of Clinical Endocrinology and Metabolism $2005904119-4123$. 
24 Taylor WH. The prevalence of diabetes mellitus in patients with primary hyperparathyroidism and among their relatives. Diabetic Medicine 19918 683-687.

25 Lee J. Odds ratio or relative risk for cross-sectional data? International Journal of Epidemiology 199423 201-203.

26 Ayesha I, Bala TS, Reddy CV \& Raghuramulu N. Vitamin D deficiency reduces insulin secretion and turnover in rats. Diabetes, Nutrition and Metabolism 200114 78-84.

27 Bourlon PM, Billaudel B \& Faure-Dussert A. Influence of vitamin D3 deficiency and 1,25 dihydroxyvitamin D3 on de novo insulin biosynthesis in the islets of the rat endocrine pancreas. Journal of Endocrinology 1999160 87-95.

28 de Souza Santos R \& Vianna LM. Effect of cholecalciferol supplementation on blood glucose in an experimental model of type 2 diabetes mellitus in spontaneously hypertensive rats and Wistar rats. Clinica Chimica Acta 2005358 146-150.

29 Borissova AM, Tankova T, Kirilov G, Dakovska L \& Kovacheva R. The effect of vitamin D3 on insulin secretion and peripheral insulin sensitivity in type 2 diabetic patients. International Journal of Clinical Practice $200357258-261$.

30 Chiu KC, Chuang LM \& Yoon C. The vitamin D receptor polymorphism in the translation initiation codon is a risk factor for insulin resistance in glucose tolerant Caucasians. BMC Medical Genetics 200122.

31 Tai K, Need AG, Horowitz M \& Chapman IM. Glucose tolerance and vitamin D: effects of treating vitamin D deficiency. Nutrition 200824 950-956.

32 Wang TJ, Pencina MJ, Booth SL, Jacques PF, Ingelsson E, Lanier K, Benjamin EJ, D'Agostino RB, Wolf M \& Vasan RS. Vitamin D deficiency and risk of cardiovascular disease. Circulation 2008117 503-511.

Received 22 July 2009

Accepted 9 August 2009 